\title{
INFLUÊNCIA DA ADUBAÇÃO FOSFATADA E DA INTRODUÇÃO DE ESPÉCIES FORRAGEIRAS DE INVERNO NA OFERTA DE FORRAGEM DE PASTAGEM NATURAL ${ }^{1}$
}

\author{
LUCIANO COLPO GATIBONI ${ }^{2}$, JOÃO KAMINSKI ${ }^{3}$, JOÃO BATISTA ROSSETTO PELLEGRINI ${ }^{4}$, \\ GUSTAVO BRUNETTO ${ }^{4}$, ADAIR SAGGIN ${ }^{4}$ e JOÃO PAULO CASSOL FLORES ${ }^{4}$
}

\begin{abstract}
RESUMO - A pecuária de corte no Estado do Rio Grande do Sul é baseada na utilização de pastagens naturais, que são de baixa produtividade e sazonalidade de produção. O objetivo deste trabalho foi testar o efeito de diferentes fosfatos, solúveis e natural, associados ou não à calagem, no melhoramento de pastagem natural pela introdução de espécies forrageiras de inverno. O estudo foi conduzido na Universidade Federal de Santa Maria, em solo Argissolo Vermelho. Os tratamentos foram: foscal (superfosfato simples + calcário); superfosfato triplo + calcário; superfosfato triplo; hiperfosfato de gafsa; sem adubação fosfatada e sem calcário; testemunha de pastagem natural. Com exceção do último, todos os tratamentos receberam adubação potássica, nitrogenada e introdução de Lolium multiflorum e Trifolium vesiculosum. Foram aplicados nos tratamentos específicos $3,2 \mathrm{Mg} \mathrm{ha}^{-1}$ de calcário (elevação do $\mathrm{pH}-\mathrm{H}_{2} \mathrm{O}$ a 5,5), $180 \mathrm{~kg} \mathrm{ha}^{-1}$ de $\mathrm{P}_{2} \mathrm{O}_{5}, 130 \mathrm{~kg} \mathrm{ha}^{-1}$ de $\mathrm{K}_{2} \mathrm{O}$ e $70 \mathrm{~kg} \mathrm{ha}^{-1}$ de $\mathrm{N}$. A produtividade de matéria seca foi avaliada nos períodos do inverno, primavera, primavera-verão e verão-outono. A adubação fosfatada aumentou significativamente a produtividade de matéria seca da pastagem. Os fosfatos solúveis proporcionaram maiores produções que o fosfato natural. A calagem não aumentou a produtividade de Lolium multiflorum e da pastagem natural, mas o Trifolium vesiculosum apresentou resposta a este insumo.
\end{abstract}

Termos para indexação: calagem, fosfatos, produtividade, gramíneas, melhoramento de pastagens.

\section{INFLUENCE OF PHOSPHORUS FERTILIZATION AND INTRODUCTION OF WINTER FORAGE SPECIES ON FORAGE OFFER FROM NATURAL PASTURE}

\begin{abstract}
The beef cattle production in Rio Grande do Sul, Brazil, is based on natural pasture grazing, which are of low productivity and seasonal growth. The present work was done to test the effects of Italian ryegrass and arrowleaf clover introduction in natural pasture under different phosphorus fertilizer, soluble and natural, associated or not to the lime, on forage improvement from natural pasture. The study was conducted at Universidade Federal de Santa Maria on a Paleudalf. The treatments were: foscal (simple superphosphate + lime); triple superphosphate + lime; triple superphosphate; rock phosphate of Gafsa; without phosphorus fertilizer and without lime, and natural pasture. Except for the last treatment, the others received potassium and nitrogen fertilizers and introduction of Lolium multiflorum and Trifolium vesiculosum. The autors used $3.2 \mathrm{Mg} \mathrm{ha}^{-1}$ of lime (elevation of the $\mathrm{pH}-\mathrm{H}_{2} \mathrm{O}$ to 5.5), $180 \mathrm{~kg} \mathrm{ha}^{-1}$ of $\mathrm{P}_{2} \mathrm{O}_{5}, 130 \mathrm{~kg} \mathrm{ha}^{-1}$ of $\mathrm{K}_{2} \mathrm{O}$ and $70 \mathrm{~kg} \mathrm{ha}^{-1}$ of $\mathrm{N}$. The productivity of dry matter was evaluated for the following periods: winter, spring, spring-summer and summer-autumn. The phosphorus fertilization increased the productivity of dry matter of the pasture and the soluble phosphates provided greater productions than the rock phosphate. The lime did not increase productivity of Lolium multiflorum and natural pasture, but Trifolium vesiculosum responded to this input.
\end{abstract}

Index terms: liming, phosphates, productivity, gramineae, pasture improvement.

1 Aceito para publicação em 6 de outubro de 1999.

Extraído da dissertação de mestrado, apresentada pelo primeiro autor à Universidade Federal de Santa Maria (UFSM), RS. Parcialmente financiado pela FAPERGS.

${ }^{2}$ Eng. Agrôn., M.Sc., aluno do curso de doutorado, Centro de Ciências Rurais (CCR), Dep. de Solos, UFSM, CEP
97105-900 Santa Maria, RS. Bolsista da Capes. E-mail: a9760363@alunop.ufsm.br

${ }^{3}$ Eng. Agrôn., Dr., CCR, Dep. de Solos, UFSM. Bolsista do CNPq. E-mail: kaminski@creta.ccr.ufsm.br

${ }^{4}$ Aluno do curso de Agronomia, UFSM. 


\section{INTRODUÇÃO}

As pastagens naturais do Rio Grande do Sul ocupam uma área de, aproximadamente, 10,5 milhões de hectares, que representam em torno de $43 \%$ da área do Estado. A exploração econômica é realizada principalmente pela bovinocultura de corte e ovinocultura. A composição botânica da pastagem é constituída predominantemente por gramíneas perenes de crescimento estival. Isto confere uma sazonalidade na produção de forragem, com produção satisfatória de matéria seca no verão, e déficit de produção no inverno (Mohrdieck, 1980). O melhoramento da pastagem natural com a introdução de espécies de estação fria é uma estratégia plausível de ser utilizada para obtenção de forragem em ambas as estações. A introdução de espécies consiste na semeadura de uma ou mais espécies forrageiras de crescimento hibernal, visando aumentar o fornecimento de forragem da pastagem para os animais. Para que isso ocorra, a adubação é indispensável para aumentar o fornecimento de nutrientes e promover o estabelecimento ou manutenção das espécies introduzidas, já que a fertilidade natural dos solos é baixa (Agostini \& Kaminski, 1976; Senger et al., 1996). Nabinger (1980) relata que nos solos sob pastagens naturais no Rio Grande do Sul, o nutriente que mais limita a produção é o fósforo (P), seguido de problemas relacionados à acidez do solo. Por isso, comumente são obtidas respostas das pastagens naturais e espécies introduzidas à adubação fosfatada. Macedo et al. (1985) testaram fosfatos solúveis, fosfatos naturais e introdução de trevobranco no melhoramento de pastagem natural. No primeiro ano, a produção de massa seca no tratamento com superfosfato triplo foi superior aos demais fosfatos, e nos três anos subseqüentes o hiperfosfato equivaleu ao superfosfato triplo.

Macedo et al. (1979) testaram durante quatro anos os efeitos da aplicação superficial de duas doses de calcário sobre a produtividade de uma pastagem natural, com introdução de espécies de inverno. Os resultados mostraram que a pastagem natural não respondeu à aplicação de calcário, porém foram observadas respostas significativas das espécies introduzidas. Oliveira \& Barreto (1976), testando o efeito de doses de calcário sobre o comportamento de gramíneas e leguminosas semeadas sobre pastagem natural em solo ArgissoloVermelho de pH 5,0, observaram aumentos de produção de massa seca das leguminosas e teor de proteína bruta da forragem, com o aumento da dose de calcário incorporado a $10 \mathrm{~cm}$ de profundidade; já a pastagem natural e as gramíneas instaladas não responderam à calagem.

Pelo exposto, observa-se que a resposta das pastagens naturais e espécies cultivadas em alguns solos do Rio Grande do Sul respondem à adubação fosfatada, mas a resposta positiva à calagem está relacionada com o material de origem do solo e a tolerância das plantas a solo ácido.

Este trabalho foi desenvolvido com o objetivo de testar o efeito de diferentes fosfatos, solúveis e natural, associados, ou não, à calagem, e da introdução de espécies forrageiras de inverno no melhoramento de pastagem natural em solo de textura superficial arenosa.

\section{MATERIAL E MÉTODOS}

O experimento foi conduzido no campus da Universidade Federal de Santa Maria, região da Depressão Central do Estado do Rio Grande do Sul. O solo utilizado foi Argissolo Vermelho, textura superficial arenosa, sob pastagem natural. A vegetação nativa existente era constituída pre-dominantemente por Paspalum notatum. O delineamento experimental utilizado foi o de blocos ao acaso, com quatro repetições. As parcelas mediam 5,6 m de largura e $10 \mathrm{~m}$ de comprimento, totalizando $56 \mathrm{~m}^{2}$ de área.

Os tratamentos testados foram: foscal - superfosfato simples + calcário; SFT + calcário - superfosfato triplo + calcário; SFT - superfosfato triplo; hiperfosfato hiperfosfato de Gafsa; sem P - introdução de espécies; testemunha - pastagem natural sem melhoramento. Com exceção deste último, todos os demais tratamentos receberam adubação potássica, nitrogenada e foram introduzidas espécies forrageiras de inverno.

As espécies forrageiras, semeadas em linha em plantio direto sobre a pastagem natural sem dessecação, foram azevém (Lolium multiflorum cv. comum) e trevo vesiculoso (Trifolium vesiculosum cv. Yuchi) nas quantidades de $30 \mathrm{e}$ $12 \mathrm{~kg} \mathrm{ha}^{-1}$ de sementes, respectivamente. A adubação com $\mathrm{P}, \mathrm{K}, \mathrm{N}$ e calagem foram usadas segundo a recomendação da Comissão de Fertilidade do solo-RS/SC (1995), nas doses de $180 \mathrm{~kg} \mathrm{ha}^{-1}$ de $\mathrm{P}_{2} \mathrm{O}_{5}, 130 \mathrm{~kg} \mathrm{ha}^{-1}$ de $\mathrm{K}_{2} \mathrm{O}$, e $3,2 \mathrm{tha}^{-1}$ de calcário para elevação do $\mathrm{pH}-\mathrm{H}_{2} \mathrm{O}$ a 5,5. Foram realiza- 
das duas adubações nitrogenadas de cobertura utilizandose 40 e $30 \mathrm{~kg} \mathrm{ha}^{-1}$ de $\mathrm{N}$ aos 40 e 70 dias após a semeadura, usando uréia como fonte de $\mathrm{N}$. A semeadura foi realizada no dia 29/5/97, quando o crescimento da pastagem natural estava paralisado pelo efeito de geadas.

Para estimativa da produção de matéria seca da pastagem foram realizados cortes utilizando quadrados de $0,25 \mathrm{~m}^{2}$, coletando-se quatro subamostras por parcela experimental. Os cortes da vegetação foram feitos a $5 \mathrm{~cm}$ do solo, toda vez que o melhor tratamento atingisse uma altura média de $20 \mathrm{~cm}$. Após cada corte a área experimental foi roçada a $5 \mathrm{~cm}$ de altura, e a palhada, retirada das parcelas. Foram realizados quatro cortes, correspondendo aos períodos de 29/5/97 a 2/10/97 (inverno); 3/10/97 a 8/11/97 (primavera); 9/11/97 a 31/1/98 (primavera-verão); e 1/2/98 a 16/4/98 (verão-outono).

\section{RESULTADOS E DISCUSSÃO}

O período de inverno (128 dias) apresentou crescimento lento da pastagem. Houve resposta da pastagem natural à aplicação de $\mathrm{K}, \mathrm{N}$ e introdução de espécies, pois no tratamento sem adição de $\mathrm{P}$, a produção de matéria seca foi superior à da testemunha (Tabela 1). Onde as espécies introduzidas apresentaram grandes produções de matéria seca, o crescimento da pastagem natural foi reduzido, mostrando assim a competição imposta pelas espécies introduzidas no período de inverno, quando a taxa de crescimento e a capacidade de competição da pastagem natural são baixas. Baixas produções de matéria seca da pastagem natural no período de inverno quando da introdução de espécies forrageiras de crescimento hibernal também foram observadas por Scholl et al. (1976).

$\mathrm{O}$ azevém não apresentou resposta à calagem, pois a produtividade deste nos tratamentos SFT + calcário e SFT sem calcário não diferiu (Tabela 1). $\mathrm{Na}$ avaliação de inverno observou-se que no tratamento com adição de hiperfosfato de Gafsa, o azevém teve menor produção que nos tratamentos com adição de fosfatos solúveis, possivelmente devido à sua lenta dissolução no solo e a conseqüente menor disponibilidade para as plantas, como alertado por Kaminski \& Peruzzo (1997). Maior produção de massa seca de azevém foi observada no tratamento foscal. Como a calagem não aumentou a produção, esta resposta pode ser atribuída ao enxofre (S) contido no superfosfato simples. Este benefício é ressaltado por Cornforth et al. (1993).

O trevo vesiculoso não teve crescimento significativo, pois sua estação de crescimento é mais tardia do que a do azevém.

$\mathrm{Na}$ oferta total de forragem do período de inverno, representada pela soma das produções de azevém, trevo e pastagem natural, observou-se resposta à calagem e à adubação fosfatada. Os tratamentos com adição de calcário foram superiores aos demais, porém ainda se observou a superioridade do tratamento com foscal. Os tratamentos com SFT, hiperfosfato e sem adição de $\mathrm{P}$, não diferiram entre si na produção total de matéria seca. A produção de forragem por parte da pastagem natural no tratamento sem $\mathrm{P}$ foi alta, pois não ocorreu alta competição do azevém.

O melhoramento da pastagem, no tratamento com foscal, triplicou a produção de forragem em relação à testemunha (crescimento médio diário de 22,3 e $6,9 \mathrm{~kg} \mathrm{ha}^{-1} \mathrm{dia}^{-1}$ ), mostrando assim que este sistema pode ser utilizado para o aumento da oferta de forragem no inverno, que é a época crítica de falta de forragem (Tabela 1).

Na primavera, o crescimento da pastagem foi intenso, pois é a estação de crescimento da pastagem natural, do trevo vesiculoso e do azevém. Por isso, nos 39 dias avaliados a pastagem ultrapassou os $20 \mathrm{~cm}$ de altura e foi cortada. Os resultados (Tabela 1) mostraram que a pastagem natural, com maior capacidade de competição com as espécies introduzidas, recuperou-se na primavera e não mostrou diferenças entre os tratamentos.

$\mathrm{O}$ azevém não respondeu à calagem. $\mathrm{O}$ tratamento com adição de foscal não diferiu do tratamento com adição de SFT sem calcário. Houve resposta à aplicação de hiperfosfato quando a produção de matéria seca foi superior à do tratamento sem adição de fósforo, porém inferior à dos tratamentos com adição de superfosfatos. $\mathrm{O}$ tratamento sem $\mathrm{P}$, mas com introdução de espécies, adubação nitrogenada e potássica, não diferiu da testemunha. Tal resultado pode ser atribuído à baixa disponibilidade de $\mathrm{P}$ no solo e conseqüente limitação deste nutriente às plantas.

Pesq. agropec. bras., Brasília, v.35, n.8, p.1663-1668, ago. 2000 
TABELA 1. Produção de matéria seca $\left(\mathrm{kg} \mathrm{ha}^{-1}\right)$ e crescimento médio diário $\left(\mathrm{kg} \mathrm{ha}^{-1} \mathrm{dia}^{-1}\right)$ de pastagem natural, azevém e trevo vesiculoso em diferentes períodos de 1997/1998 .

\begin{tabular}{|c|c|c|c|c|c|}
\hline Tratamento $^{2}$ & Pastagem natural & Azevém & Trevo vesiculoso & Total & $\mathrm{CMD}^{3}$ \\
\hline & \multicolumn{5}{|c|}{ Inverno $(29 / 5 / 97$ a $2 / 10 / 97)$} \\
\hline Foscal & $589 \mathrm{c}$ & $2.244 \mathrm{a}$ & $12 \mathrm{a}$ & $2.846 \mathrm{a}$ & 22,3 \\
\hline SFT + calcário & $443 d$ & $1.579 \mathrm{~b}$ & $0 \mathrm{a}$ & $2.022 b$ & 15,8 \\
\hline SFT & $152 \mathrm{e}$ & $1.540 \mathrm{~b}$ & $0 \mathrm{a}$ & $1.692 \mathrm{c}$ & 13,2 \\
\hline Hiperfosfato & $392 d$ & $1.082 \mathrm{c}$ & $0 \mathrm{a}$ & $1.474 \mathrm{c}$ & 11,5 \\
\hline Sem P & $1.083 \mathrm{a}$ & $383 d$ & $0 \mathrm{a}$ & $1.466 \mathrm{c}$ & 11,4 \\
\hline Testemunha & $882 b$ & $0 \mathrm{e}$ & $0 \mathrm{a}$ & $882 d$ & 6,9 \\
\hline $\mathrm{CV}(\%)$ & 13,65 & 14,27 & 489,90 & 11,63 & - \\
\hline \multicolumn{6}{|c|}{ Primavera $(3 / 10 / 97$ a $8 / 11 / 97)$} \\
\hline Foscal & $681 \mathrm{a}$ & $2.475 \mathrm{a}$ & $248 \mathrm{a}$ & $3.404 \mathrm{a}$ & 87,3 \\
\hline SFT + calcário & $651 \mathrm{a}$ & $1.907 \mathrm{~b}$ & $128 b$ & $2.686 b$ & 68,8 \\
\hline SFT & $752 \mathrm{a}$ & $2.236 \mathrm{ab}$ & $62 c$ & $3.050 \mathrm{ab}$ & 78,1 \\
\hline Hiperfosfato & $685 a$ & $1.517 \mathrm{c}$ & Od & $2.202 \mathrm{c}$ & 56,5 \\
\hline Sem P & $698 \mathrm{a}$ & $165 d$ & $0 \mathrm{~d}$ & $863 d$ & 22,2 \\
\hline Testemunha. & $733 \mathrm{a}$ & Od & $0 \mathrm{~d}$ & $733 d$ & 18,8 \\
\hline $\mathrm{CV}(\%)$ & 15,96 & 18,53 & 14,97 & 13,88 & - \\
\hline \multicolumn{6}{|c|}{ Primavera-verão (9/11/97 a 31/1/98) } \\
\hline Foscal & $2.600 \mathrm{a}$ & 0 & $54 \mathrm{a}$ & $2.654 \mathrm{a}$ & 31,9 \\
\hline SFT + calcário & $2.103 \mathrm{ab}$ & 0 & $0 \mathrm{~b}$ & $2.103 \mathrm{bc}$ & 25,3 \\
\hline SFT & $2.334 \mathrm{a}$ & 0 & $0 \mathrm{~b}$ & $2.334 \mathrm{ab}$ & 28,1 \\
\hline Hiperfosfato & $2.127 \mathrm{ab}$ & 0 & $0 b$ & $2.127 \mathrm{bc}$ & 25,6 \\
\hline Sem P & $1.749 \mathrm{bc}$ & 0 & $\mathrm{Ob}$ & $1.749 \mathrm{~cd}$ & 21,1 \\
\hline Testemunha. & $1.482 \mathrm{c}$ & 0 & $0 \mathrm{~b}$ & $1.482 \mathrm{~d}$ & 17,9 \\
\hline $\mathrm{CV}(\%)$ & 15,08 & - & 15,76 & 15,02 & - \\
\hline \multicolumn{6}{|c|}{ Verão-outono (1/2/98 a 16/4/98) } \\
\hline Foscal & $2.182 \mathrm{a}$ & 0 & 0 & $2.182 \mathrm{a}$ & 29,1 \\
\hline SFT + calcário & $1.988 \mathrm{a}$ & 0 & 0 & $1.988 \mathrm{a}$ & 26,5 \\
\hline SFT & $2.014 \mathrm{a}$ & 0 & 0 & $2.014 \mathrm{a}$ & 26,9 \\
\hline Hiperfosfato & $1.639 \mathrm{~b}$ & 0 & 0 & $1.639 \mathrm{~b}$ & 21,9 \\
\hline Sem P & $1.491 \mathrm{~b}$ & 0 & 0 & $1.491 \mathrm{~b}$ & 19,9 \\
\hline Testemunha & $1.045 \mathrm{c}$ & 0 & 0 & $1.045 \mathrm{c}$ & 13,9 \\
\hline $\mathrm{CV}(\%)$ & 11,70 & - & - & 11,70 & - \\
\hline \multicolumn{6}{|c|}{ Total $(29 / 5 / 97$ a $16 / 4 / 98)$} \\
\hline Foscal & $6.051 \mathrm{a}$ & $4.719 a$ & $301 \mathrm{a}$ & $11.071 \mathrm{a}$ & 34,1 \\
\hline SFT + calcário & $5.184 b$ & $3.486 \mathrm{~b}$ & $128 b$ & $8.798 b$ & 27,1 \\
\hline SFT & $5.243 b$ & $3.776 b$ & $62 c$ & $9.081 \mathrm{~b}$ & 27,9 \\
\hline Hiperfosfato & $4.844 \mathrm{bc}$ & $2.599 \mathrm{c}$ & Od & $7.443 \mathrm{c}$ & 22,9 \\
\hline Sem P & $5.021 b$ & $548 d$ & $0 d$ & $5.569 \mathrm{~d}$ & 17,1 \\
\hline Testemunha & $4.141 \mathrm{c}$ & $0 \mathrm{e}$ & $0 \mathrm{~d}$ & $4.141 \mathrm{e}$ & 12,7 \\
\hline $\mathrm{CV}(\%)$ & 9,98 & 9,65 & 13,36 & 8,44 & - \\
\hline
\end{tabular}

O trevo vesiculoso, na primavera, apresentou resposta significativa à adubação com fosfatos solúveis e à calagem, sendo o tratamento com foscal o mais produtivo, possivelmente pela presença de $\mathrm{S}$ na formulação do superfosfato simples, seguido do com SFT e calcário e do com SFT sem calcário (Tabela 1). Os tratamentos com hiperfosfato e os sem adição de P não tiveram produção de matéria seca de trevo, o que mostra que esta espécie exige alta dis- ponibilidade de $\mathrm{P}$, e que a quantidade disponibilizada através da adição de hiperfosfato foi insuficiente para suprir as necessidades desta cultura. A produtividade de trevo foi muito baixa, provavelmente por problemas de inoculação, pois mesmo com a inoculação das sementes com rizóbio específico, foi observado plantas com muito poucos nódulos nas raízes e com sintomas de deficiência de $\mathrm{N}$. 
No período de primavera, o melhor tratamento apresentou um crescimento médio diário 4,6 vezes maior que o da testemunha de pastagem natural (Tabela 1).

O terceiro período de avaliação foi realizado na primavera-verão (83 dias). A pastagem natural retomou seu ritmo de crescimento e respondeu à adubação fosfatada (Tabela 1). Os tratamentos com adição de P não diferiram entre si, mas foram superiores aos tratamentos sem P. A participação de azevém foi nula, pois este já havia encerrado seu ciclo.

O trevo vesiculoso só ocorreu no tratamento com foscal, e nos demais não houve produção. Isto possivelmente tenha ocorrido por causa da adição de S, que lhe conferiu, além de maior produtividade, maior longevidade produtiva.

Na produção total deste período, os melhores tratamentos foram foscal e SFT sem calcário, que não diferiram entre si. A calagem não trouxe aumentos significativos de produção de matéria seca. O tratamento com hiperfosfato não diferiu dos tratamentos com adição de SFT e calcário e SFT sem calcário. Os tratamentos sem adição de $P$ não diferiram entre si. Neste período o melhor tratamento apresentou um crescimento médio diário $1,7 \mathrm{vez}$ maior que a testemunha, uma diferença de produtividade menor que nos períodos anteriores, devido ao término do ciclo produtivo das espécies introduzidas, que possuem potencial de resposta aos insumos superior ao da pastagem natural.

No período de verão-outono (75 dias), só houve contribuição da pastagem natural na produção de forragem, pois as espécies introduzidas já haviam encerrado o seu ciclo produtivo. A pastagem natural respondeu melhor à aplicação de fontes de $\mathrm{P}$ solúveis, já que os tratamentos com adição de foscal, SFT com calcário e SFT sem calcário, não diferiram entre si mas foram superiores aos demais tratamentos, também não houve resposta da pastagem natural à calagem (Tabela 1). A aplicação de hiperfosfato de gafsa não trouxe benefícios à pastagem, pois a produção desta não diferiu daquela cujo tratamento era sem adição de P. O tratamento-testemunha foi estatisticamente inferior aos demais. $\mathrm{O}$ crescimento médio diário do melhor tratamento foi 2,1 vezes maior que o da testemunha.

No somatório dos quatro períodos de avaliação (325 dias), os resultados mostraram que a pastagem natural respondeu à aplicação de foscal. Não foi observada a resposta à calagem, já que o tratamento com adição de SFT e calcário não diferiu do tratamento com aplicação de SFT sem calcário. Os tratamentos SFT com calcário, SFT, hiperfosfato e sem P não diferiram entre si, mas foram superiores à testemunha, exceto o hiperfosfato (Tabela 1). Estes resultados mostraram que na produção total, a pastagem natural não apresentou respostas à aplicação de $\mathrm{P}$; porém, ressalta-se que isso se deveu à competição imposta pelas espécies introduzidas no período de inverno, que acarretou na diminuição da produção de matéria seca da pastagem natural naqueles tratamentos com altas produtividades por parte das espécies introduzidas. Com isso, não houve diferença estatística entre aqueles tratamentos com adição de $\mathrm{P}$ e o sem adição de $\mathrm{P}$, mas com $\mathrm{N}$ e $\mathrm{K}$.

Na produção total de azevém, observou-se que ele não respondeu à calagem, o que concorda com as afirmações de Morris et al. (1992), que classificam esta espécie como tolerante a solos ácidos. O azevém respondeu à aplicação de $\mathrm{P}$, e o melhor tratamento foi o tratamento com aplicação de foscal, provavelmente pela presença de S. A adição de fosfatos solúveis proporcionou produções de matéria seca superiores ao tratamento com aplicação de fosfato natural, mostrando, assim, que o azevém é responsivo à adubação fosfatada, e também é exigente quanto à disponibilidade deste elemento no solo.

$\mathrm{O}$ trevo vesiculoso, neste experimento, mostrouse responsivo à fontes de $\mathrm{P}$ e à calagem, como alertado por Kaminski (1989), que diz que geralmente as leguminosas são mais sensíveis aos efeitos de solo ácido que as gramíneas. O tratamento que proporcionou a maior produtividade foi o com foscal, seguido do com SFT e calcário, sendo que no tratamento sem calagem a participação do trevo foi irrisória.

Na produção total de matéria seca do experimento observou-se resposta da pastagem à adubação fosfatada. $\mathrm{O}$ tratamento com adição de foscal foi estatisticamente superior aos demais, seguido dos tratamentos com adição de SFT com calcário e SFT sem calcário, os quais não diferiram entre si. Não houve resposta à calagem, porque o azevém e a pastagem natural, que representaram a maior parte da produção de forragem, não responderam a esse insumo, e o incremento de produção de trevo pela calagem não foi suficiente para influir na produção total da pastagem. O tratamento com adição de hiperfosfato foi 
superior ao tratamento sem adição de $\mathrm{P}$, mas inferior aos tratamentos com fosfatos solúveis, mostrando assim, que neste tratamento houve disponibilidade menor de $\mathrm{P}$ às plantas do que nos tratamentos com adição de fosfatos solúveis.

No total das produções de matéria seca, a produção de forragem no melhor tratamento foi 2,6 vezes maior que a da testemunha.

\section{CONCLUSÕES}

1. A adubação fosfatada aumenta a produtividade de matéria seca da pastagem, e os fosfatos solúveis proporcionam maiores produções que o fosfato natural.

2. O calcário não aumenta a produtividade do azevém e da pastagem natural, mas o trevo vesiculoso apresenta resposta a este insumo.

3. O melhoramento da pastagem pela introdução de espécies forrageiras de inverno e adubação aumenta a oferta de forragem da pastagem no período hibernal e estival.

\section{REFERÊNCIAS}

AGOSTINI, J.A.E.; KAMINSKI, J. Estudo preliminar das concentrações de nutrientes minerais de solos e pastagens naturais ocorrentes em diferentes regiões do Rio Grande do Sul. Revista Centro de Ciências Rurais, Santa Maria, v.6, n.4, p.385-406, 1976.

COMISSÃO DE FERTILIDADE DO SOLO-RS/SC (Passo Fundo, RS). Recomendação de adubação e calagem para os Estados do Rio Grande do Sul e Santa Catarina. 3.ed. Passo Fundo : Sociedade Brasileira de Ciência do Solo/Embrapa-CNPT, 1995. 224p.

CORNFORTH, I.S.; SINCLAIR, A.G.; ROWARTH, J.S. The nutrition of grazed pastures in New Zealand. Plant and Soil, Dordrecht, v.155/156, p.227-230, 1993.

KAMINSKI, J. Acidez dos solos e a fisiologia das plantas. In: SEMINÁRIO SOBRE CORRETIVOS DA ACIDEZ DO SOLO, 2., 1989, Santa Maria. Anais. Santa Maria : Universidade Federal de Santa Maria, 1989. p.39-61.
KAMINSKI, J.; PERUZZO, G. Eficácia de fosfatos naturais reativos em sistemas de cultivo. Santa Maria : Sociedade Brasileira de Ciência do Solo, 1997. 31p. (Boletim Técnico, 3).

MACEDO, W.; BRASIL, N.E.; PATELLA, J.F. Calcário na implantação em cobertura de leguminosa de inverno. Pesquisa Agropecuária Brasileira, Brasília, v.14, n.2, p.125-134, abr. 1979.

MACEDO, W.; GONÇALVES, J.O.N.; GIRARDIDEIRO, A.M. Melhoramento de pastagem natural com fosfatos e introdução de leguminosas em solo da fronteira oeste do Rio Grande do Sul. Revista Brasileira de Ciência do Solo, Campinas, v.9, n.3, p.231-235, 1985.

MOHRDIECK, K.H. Formações campestres do Rio Grande do Sul. In: SEMINÁRIO SOBRE PASTAGENS "DE QUE PASTAGENS NECESSITAMOS", 1980, Porto Alegre. Anais. Porto Alegre : FARSUL, 1980. p.18-27.

MORRIS, D.R.; JOOST, R.E.; CORKERN, D.L.; MASON, L.F. Liming double-cropped ryegrass and sorghum. Soil Science Society of America. Journal, Madison, v.56, p.155-160, 1992.

NABINGER, C. Técnicas de melhoramento de pastagens naturais no Rio Grande do Sul. In: SEMINÁRIO SOBRE PASTAGENS “DE QUE PASTAGENS NECESSITAMOS”, 1980, Porto Alegre. Anais. Porto Alegre : FARSUL, 1980. p.28-58.

OLIVEIRA, O.L.; BARRETO, I.L. Efeito de calcário e método de semeadura no comportamento de espécies forrageiras temperadas no melhoramento de pastagem natural. Pesquisa Agropecuária Brasileira, Série Zootecnia, Rio de Janeiro, v.11, n.5, p.49-56, 1976.

SCHOLL, J.M.; LOBATO, J.F.P.; BARRETO, I. Improvement of pastures by direct seeding into native grass in Southern Brazil with oats, and with nitrogen supplied by fertilizer or arrowleaf clover. Turrialba, San José, v.26, n.2, p.144-149, 1976.

SENGER, C.C.D.; SANCHEZ, L.M.B.; PIRES, M.B.G.; KAMINSKI, J. Teores minerais em pastagens do Rio Grande do Sul. I. Cálcio, fósforo, magnésio e potássio. Pesquisa Agropecuária Brasileira, Brasília, v. 31, n. 12, p.897-904, dez. 1996. 